\title{
Avaliação da Aplicabilidade do Technology Readiness Index (TRI) para a Adoção de Produtos e Serviços Baseados em Tecnologia
}

\author{
Rosana Vieira de Souza \\ Fernando Bins Luce
}

\begin{abstract}
Resumo
A prontidão para tecnologia refere-se à propensão dos indivíduos a adotar produtos e serviços tecnológicos a partir de condutores e inibidores mentais relacionados ao otimismo, inovatividade, desconforto e insegurança. Sua mensuração se dá por meio do Technology Readiness Index (TRI), instrumento de medida desenvolvido por Parasuraman (2000) e Parasuraman e Colby (2001). A partir disso, o objetivo central deste trabalho é apresentar os resultados de uma investigação que buscou validar o TRI para o contexto brasileiro, por meio da reaplicação do instrumento de medida a uma amostra de 731 consumidores. A validade do TRI foi verificada com o auxílio da análise fatorial confirmatória via estratégia de confirmação de modelo. Tal avaliação foi complementada com a comparação entre os escores dos respondentes do TRI, agrupados por categorias de posse e uso de produtos/serviços tecnológicos e por categorias de prontidão para a tecnologia. Este estudo oferece algumas evidências sobre a capacidade do TRI de distinguir usuários de não usuários destes produtos e de predizer comportamentos de adoção, mas sinaliza a necessidade de novas investigações sobre a estrutura interna do instrumento.
\end{abstract}

Palavras-chave: adoção de tecnologia; comportamento do consumidor; mensuração.

\begin{abstract}
Technology-readiness refers to people's propensity to adopt technological products and services. The construct can be viewed as an overall state of mind resulting from mental drivers and inhibitors related to the optimism, innovativeness, discomfort and insecurity. Technology Readiness Index (TRI) is the scale developed by Parasuraman (2000) and Parasuraman and Colby (2001) for measurement of the consumers' technology-readiness. The main purpose of this study is to evaluate the applicability of TRI in the brazilian context through the replication of the scale to a sample of 731 consumers. The quality of TRI was proven by confirmatory-factor analysis through confirmatory modeling strategy. Such evaluation was complemented with the exam of the association between respondents' TRI scores and their answers to a number of questions pertaining to ownership and use of technology-based products and services. This study offers some evidences of TRI's ability to discriminate well between users and nonusers of these products and to predict adoption behaviors, but suggest there is a need for new studies about the factor structure of the technology readiness construct.
\end{abstract}

Key words: technology adoption; consumer behavior; measurement. 


\section{INTRODUÇÃO}

Os avanços tecnológicos, nas últimas décadas, vêm produzindo impacto considerável na forma como consumidores passam a lidar com produtos cada vez mais sofisticados e no modo como os serviços são produzidos e entregues. Um dos principais desafios para as empresas que pretendem promover seus produtos e serviços, baseados em tecnologia, é assegurar a adoção de tais produtos e a satisfação dos consumidores.

Parasuraman e Colby (2001) destacam que o principal motivo das ações inadequadas de marketing para produtos e serviços, baseados em tecnologia, é a compreensão equivocada das atitudes dos clientes em relação à tecnologia e das variações dessas atitudes nos diferentes segmentos de clientes. Embora o desenvolvimento tecnológico propicie benefícios inquestionáveis quanto a aspectos de conveniência, eficiência e rapidez, por meio da entrega de serviços por autoatendimento, por exemplo, diversas pesquisas têm destacado os sentimentos negativos experienciados por consumidores em suas relações com produtos tecnológicos, tais como computadores, caixas automáticos, aparelhos de fax e secretária eletrônica, entre outros, resultando na crescente frustração para interagir com a tecnologia (MEUTER et al., 2000; MITCHELL, 1994; PARASURAMAN, 2000; ROSEN; SEARS; WEIL, 1987).

Outras pesquisas procuraram investigar as reações do consumidor diante da tecnologia (COWLES, 1989; COWLES; CROSBY, 1990), e apontaram os paradoxos subjacentes à adoção de tecnologia (MICK; FOURNIER, 1998), segundo os quais os comportamentos de consumo de tecnologia são permeados por crenças e sentimentos ambíguos de controle e caos, competência e incompetência, liberdade e escravização, entre outros. Apesar desses esforços mais recentes, existem ainda poucas investigações sobre a prontidão dos consumidores para usar produtos e serviços baseados em tecnologia. Em geral, em que grau as pessoas estão prontas para adotar e usar efetivamente novas tecnologias?

Com base nestas reflexões e no estudo desenvolvido por Parasuraman e Colby (2001), que propuseram o Technology Readiness Index (TRI) como instrumento de medida da prontidão para a tecnologia do consumidor norte-americano, surgem algumas indagações, das quais podem ser derivados os propósitos deste trabalho: a escala utilizada no contexto americano pode ser aplicada em outros ambientes, mais especificamente, para medir a prontidão para tecnologia de consumidores 
brasileiros? O TRI pode ser considerado uma forma de mensuração confiável e válida para um ambiente diferente do seu país de origem? O TRI é um bom preditor dos comportamentos de compra relativos à tecnologia?

Assim sendo, o objetivo central deste trabalho é apresentar os resultados de uma investigação que buscou validar o TRI para o contexto brasileiro. O texto está organizado da seguinte maneira: inicialmente são apresentados o constructo prontidão para a tecnologia e o desenvolvimento do TRI original; na seqüência, a descrição dos principais procedimentos metodológicos utilizados na investigação; a seguir os principais resultados da validação do TRI, incluindo a discussão das implicações gerenciais da sua utilização; e por fim as considerações finais com menção às limitações do estudo.

\section{A Prontidão para Tecnologia e o TRI}

A prontidão para tecnologia ${ }^{(1)}$ (TR - Technology Readiness) diz respeito à propensão dos indivíduos para adotar novas tecnologias. Em outras palavras, é o estado resultante de condutores e inibidores mentais que, em conjunto, determinam a predisposição do indivíduo para interagir com produtos e serviços baseados em tecnologia (PARASURAMAN, 2000). Tais condutores e inibidores da adoção de tecnologia são refletidos, segundo Parasuraman e Colby (2001), por 4 diferentes dimensões que compõem o constructo em estudo, quais sejam:

1) Otimismo. Dimensão que representa as visões positivas em relação à tecnologia e às crenças de que esta propicia aos indivíduos maior controle, flexibilidade e eficiência nas suas vidas.

2) Inovatividade. Representa uma tendência do indivíduo a ser pioneiro na adoção de tecnologia ou líder de opinião.

3) Desconforto. Denota a percepção de falta de controle sobre a tecnologia e o sentimento de ser oprimido por ela.

4) Insegurança. Denota desconfiança da tecnologia e ceticismo com relação às próprias habilidades em utilizá-la de forma apropriada.

Desta forma, otimismo e inovatividade constituiriam, na ótica de Parasuraman e Colby (2001), os condutores da prontidão para tecnologia, ou seja, indicariam fatores que motivam os indivíduos à adoção de novas tecnologias. Por outro lado, as dimensões desconforto e insegurança constituiriam inibidores, isto é, representariam fatores que retardam ou impedem a adoção. As dimensões 
condutoras e inibidoras da prontidão para tecnologia atuam independentemente, de forma que uma pessoa pode apresentar qualquer combinação de motivações ou inibições.

A prontidão geral para a tecnologia do consumidor é dada, portanto, pela combinação das quatro dimensões, e não apenas pela capacidade técnica do indivíduo ou rapidez com que adota uma nova tecnologia. Isto significa dizer que não se baseia somente na dimensão inovatividade, mas em elementos relacionados ao otimismo, desconforto, insegurança e também inovatividade. De acordo com Parasuraman e Colby (2001), o Technology Readiness Index (TRI) é formado por 4 fatores com 36 indicadores da prontidão para tecnologia.

Ainda que a investigação dos autores forneça indícios da qualidade do instrumento e da sua capacidade de predizer comportamentos de compra, faz-se necessário testar o TRI em contextos diferentes daquele da sua origem, o que foi realizado por meio da reaplicação do instrumento de medida no contexto brasileiro. Trata-se, mais especificamente, de estudo descritivo de corte transversal com consumidores finais em região metropolitana do país.

\section{Procedimentos Metodológicos}

O estudo envolveu uma etapa exploratória e uma etapa descritiva. A etapa exploratória ocupou-se, fundamentalmente, da equivalência idiomática do TRI, elaboração e pré-teste do instrumento de coleta. Foi utilizada a técnica de tradução reversa, que resultou na versão final (ver Anexo). O instrumento de coleta foi dividido em cinco blocos, explicitados em seguida.

1) Posse de produtos/serviços tecnológicos. Questões relativas ao acesso, em casa, a diversos produtos ou serviços baseados em tecnologia (TV por assinatura, secretária eletrônica, identificador de chamadas telefônicas, telefone celular, computador e internet, aparelho de fax, aparelho de DVD e Palm Top). Os entrevistados deveriam utilizar uma escala nominal com três opções de respostas: já possui, pretende adquirir nos próximos 12 meses ou não pretende adquirir.

2) Uso de serviços tecnológicos. Questões sobre o uso específico de serviços baseados em tecnologia (caixa automático, transação bancária por sistema telefônico automatizado e transação pela internet, particularmente as compras realizadas pela internet de acordo com três diferentes categorias de valores dos bens: menor que $R \$ 25,00$, entre $R \$ 25,00$ e $R \$ 250,00$, maior que 
$\mathrm{R}$ \$250,00). Os entrevistados deveriam utilizar uma escala nominal com três opções de respostas: usou nos últimos 12 meses, pretende usar nos próximos 12 meses ou não pretende usar.

3) Desejo de uso futuro. Questões referentes ao grau de desejo de relacionarse com serviços futuristas, baseados em tecnologia (ver Tabela 5). Os entrevistados deveriam utilizar uma escala intervalar, atribuindo pontuações de 1 a 6, sendo 1 referente a Muito indesejável e 6 referente a Muito desejável.

4) Escala TRI: 36 afirmações sobre a tecnologia, envolvendo aspectos relativos ao otimismo, inovatividade, desconforto e insegurança com produtos e serviços baseados em tecnologia (ver Anexo). Os entrevistados deveriam utilizar uma escala intervalar, atribuindo pontuações de 1 a 5, sendo 1 referente a Discordo Totalmente e 5 referente a Concordo Totalmente.

5) Caracterização do entrevistado. Questões referentes às características dos respondentes quanto à faixa etária, estado civil, grau de instrução, profissão/ocupação, renda familiar e sexo.

A etapa descritiva contemplou a aplicação da pesquisa de campo e posterior avaliação do instrumento utilizado, a partir de procedimentos estatísticos pertinentes aos objetivos do estudo. O universo da pesquisa incluiu homens e mulheres acima de 18 anos, tal como no estudo original. A base de dados foi composta com a utilização de um cadastro de clientes de concessionárias de veículos das classes A, B e C, da área metropolitana de uma capital brasileira.

Para a definição do tamanho da amostra, foram considerados dois fatores: (1) os pressupostos básicos apresentados por Hair et al. (1998) para a adequada realização da análise fatorial, entre 10 a 20 casos por variável; e (2) a necessidade de, em um segundo momento, dividir a amostra em segmentos distintos de consumidores, mantendo, ainda assim, um número suficiente de casos para análises subseqüentes. Assim, o tamanho da amostra foi definido em 720 casos, ou 36 variáveis x 20 casos. No final, contou-se com número ligeiramente maior de casos, totalizando 731 entrevistas, que corresponderam a uma taxa de 18,8 \% de aproveitamento dos contatos efetuados. A coleta de dados ocorreu entre os dias 17 de maio e $1^{\circ}$ de junho de 2002, por meio de entrevistas telefônicas assistidas por computador ou CATI (Computer-assisted telephone interviewing). No final da coleta, os dados registrados diretamente no questionário computadorizado foram transferidos para uma planilha Excel e, a seguir, processados com o uso dos softwares estatísticos SPSS $^{\oplus}$ e AMOS $^{\circledast}$. 


\section{Análise dos Dados}

As análises envolveram os seguintes procedimentos:

- Análise do banco de dados para avaliar a sua compatibilidade com os requisitos da modelagem de equações estruturais (outliers, normalidade) e seleção do método de estimação (utilização do MLE - maximum likelihood estimation).

- Análise multivariada, envolvendo Análise Fatorial Exploratória para determinação da estrutura subjacente do conjunto de dados proveniente da pesquisa.

- Análise multivariada, envolvendo Análise Fatorial Confirmatória (AFC) da estrutura encontrada, a fim de verificar a unidimensionalidade, confiabilidade, validade convergente e discriminante das dimensões relacionadas à prontidão para a tecnologia. Optou-se pela estratégia de confirmação de modelo (HAIR et al., 1998), procedendo-se à análise fatorial confirmatória. Foram utilizados os índices de ajustamento comumente relatados na literatura, bem como os valores aceitáveis, segundo orientação de Bagozzi (1994) e Hair et al. (1998).

- Análise univariada, envolvendo teste de diferença de médias por meio da análise da variância (One-Way ANOVA), visando à comparação entre os escores dos respondentes do TRI, agrupados por categorias de posse, e uso de produtos e serviços tecnológicos e categorias de prontidão para a tecnologia.

\section{Análise dos Resultados}

A validade de constructo é verificada: (1) a partir da análise fatorial confirmatória das dimensões encontradas; e (2) a partir da comparação entre os escores dos respondentes do TRI, agrupados por categorias de posse e uso de produtos e serviços tecnológicos e categorias de prontidão para a tecnologia.

\section{Estrutura do TRI}

Procedeu-se à análise fatorial exploratória, por meio da análise de componentes principais (teste de esfericidade de Bartlett $=10967,739 ; \mathrm{p}=0,0000 / \mathrm{KMO}-$ Kaiser-Meyer-Olkin = 0,90). As tentativas iniciais de extração dos fatores relacionados à prontidão para tecnologia (rotação ortogonal Varimax) não resultaram em uma estrutura fatorial satisfatória. Este exame exploratório do 
conjunto de dados permitu observar que não houve confirmação da estrutura de 4 fatores, indicada por Parasuraman (2000). Os procedimentos realizados indicaram a necessidade de retirada de alguns itens (variáveis 22 e 27), a fim de melhorar a estrutura interna da escala, o que se confirmou como sendo o mais adequado nas análises subseqüentes. Uma solução com 6 fatores se mostrou a mais adequada, respondendo por uma variância explicada de 57,3\%. Os 6 fatores encontrados foram assim denonimados:

1) Otimismo (itens 1 a 10). Indica a faceta que responde pela maior parte da variância do constructo prontidão para tecnologia (25,3\%). Nesse estudo, a dimensão otimismo comporta-se tal como no estudo original. Embora a variável 4 você prefere usar a tecnologia mais avançada disponível tenha apresentado carga fatorial elevada, tanto no fator otimismo quanto no fator inovatividade, optou-se por mantê-la no primeiro, por dois motivos: (1) conceitualmente, a variável em tela está mais relacionada a preferências, visões e crenças positivas sobre a tecnologia, culminando em uma idéia de otimismo, do que demonstre efetivamente uma tendência do indivíduo a ser pioneiro na adoção de tecnologia. Está, portanto, mais próxima do significado que os demais itens do fator otimismo pretendem assumir do que do conjunto de itens do fator inovatividade (afirmativas de como, efetivamente, o indivíduo lida com a tecnologia). (2) Embora com coeficientes Alfa elevados nos dois fatores, a reespecificação da variável 4 para o fator otimismo contribuiu para a elevação da confiabilidade deste, de 0,8292 para 0,8504, sem diminuição significativa da confiabilidade do fator inovatividade. É válido acrescentar que esta variável também demonstrou, na primeira coleta de dados, realizada por Parasuraman e Colby (2001), certa ambigüidade, com cargas igualmente elevadas nos dois fatores.

2) Inovatividade (itens 11 a 17). Responde por 12\% da variância total explicada. A estrutura encontrada se comporta tal como no estudo original e, portanto, manteve a mesma denominação.

3) Insegurança com a Informação (itens 28 a 31). Responde por 6\% da variância total. O fator reflete uma dimensão de insegurança, como sugere Parasuraman (2000), movida pela desconfiança em relação à tecnologia. Verifica-se, entretanto, na análise do conteúdo dos itens retidos, que há preocupação específica relacionada à segurança ou integridade das informações. Todos os itens expressam o receio de que informações pessoais possam ser vistas por outras pessoas ou denotem algum tipo de desconfiança em relação à forma eletrônica como único meio de transação com uma empresa. Weber e Roehl (1999) já mostraram, em estudo sobre 
uso da internet, que a segurança é uma questão crítica para 77,8\% dos usuários, segundo os quais fornecer o número do cartão de crédito é o maior motivo de não efetuarem compras on-line.

4) Desconforto com o Constrangimento (itens 18, 19, 20, 21, 23 e 26). Responde por 5,6\% da variância total. Constitui a dimensão de desconforto e refere-se à percepção de falta de controle sobre a tecnologia ou ao sentimento de ser oprimido por ela. De maneira semelhante à dimensão de insegurança, observa-se um possível desdobramento na interpretação da dimensão de desconforto. O fator em exame revela sentimentos específicos de desconforto, bastante relacionados ao constrangimento gerado pela falta de conhecimento ou capacidade de lidar com a tecnologia e sua linguagem. Este constrangimento pode estar relacionado à sensação de falta de privacidade, evidenciada na variável 26: Novas tecnologias tornam muito fácil para o governo e as empresas espionar as pessoas. Embora tenha apresentado cargas fatoriais significativas em dois fatores, entende-se que essa variável representa, de forma mais acentuada, uma idéia de desconforto ou opressão, distanciando-se do sentido assumido pelo terceiro fator.

5) Insegurança pela falta de Contato Pessoal (itens 32 a 36). Responde por 4,5\% da variância total e emerge, neste estudo, como desdobramento do terceiro fator. O que se observa é um tipo particular de insegurança, cuja ênfase se dá na importância do contato humano e, adicionalmente, na necessidade de tangibilização das relações por meio da confirmação material de uma transação realizada. Essas questões estariam, para o consumidor, ameaçadas pela automatização. Segundo Mitchell (1994), a aversão de certos indivíduos por produtos e serviços baseados em tecnologia tem como importante elemento a preferência pela interação humana ou contato pessoal.

6) Desconforto com o Risco funcional e físico (itens 24 e 25). Responde por 3,7\% da variância total. Embora representado por apenas dois itens, expressa outra faceta da dimensão de desconforto. Enquanto o quarto fator envolve a idéia de constrangimento diante da falta de habilidade em lidar com a tecnologia, o sexto fator remete ao desconforto pelo risco percebido, quer pelo risco funcional, quer pelo risco físico. $\mathrm{O}$ risco funcional refere-se à incerteza sobre o desempenho esperado, neste caso, relacionado ao funcionamento de uma determinada tecnologia. O risco físico diz respeito ao risco percebido para si próprio ou para os outros que o produto possa impor. 
Apresentados os resultados referentes à estrutura fatorial do TRI, procurouse investigar se as diferenças entre os resultados da mensuração estão refletindo as reais diferenças entre os objetos ou indivíduos em relação às características avaliadas.

\section{Validade de Constructo}

De acordo com Garver e Mentzer (1999), a avaliação do instrumento de medida compreende uma série de propriedades, que devem ser satisfeitas para que a validade de constructo seja alcançada. Estas propriedades referem-se à unidimensionalidade, confiabilidade, validade convergente e discriminante dos constructos do modelo de mensuração, representado pela escala que está sendo analisada. A análise fatorial confirmatória foi a técnica empregada para tais análises. Posteriormente, foi realizada ainda a comparação dos escores dos respondentes do TRI, agrupados por categorias de posse e uso e categorias de prontidão para a tecnologia.

Primeiramente, é importante destacar que a dimensão Desconforto com o risco funcional e físico, composta pelas variáveis v24 (deveria haver cuidado ao substituir tarefas desempenhadas por pessoas pela tecnologia, pois novas tecnologias podem falhar) e v25 (muitas das novas tecnologias apresentam riscos à saúde ou à segurança, que não são descobertos até que as pessoas tenham utilizado a tecnologia) não apresentou resultados adequados para a realização da análise fatorial confirmatória. A dimensão apresentou graus de liberdade negativos, impossibilitando que o modelo possa ser identificado e mensurado. Dillon et al. (1997) comentam que um constructo latente deve conter, no mínimo, três variáveis, para que este possa ser identificado, o que caracteriza uma das limitações da técnica de análise fatorial confirmatória. Em situações como esta, consideradas comuns em pesquisas de marketing, por alguns autores (BAGOZZI, 1994; HAIR et al., 1998), os pesquisadores devem excluir o constructo da análise, para não prejudicar o modelo completo. Trez (2000) relatou situação similar em seu estudo, optando pela retirada do constructo com apenas duas variáveis, do modelo.

Desta forma, a dimensão Desconforto com o Risco funcional e físico não foi avaliada segundo a análise fatorial confirmatória, individualmente ou em conjunto, com as demais dimensões que formam o constructo prontidão para tecnologia. Neste caso, o processo de validação a seguir foi realizado a partir de um modelo de 5 fatores, excluindo-se a referida dimensão.

O critério utilizado para avaliar a unidimensionalidade a partir da análise fatorial confirmatória do modelo de 5 fatores seguiu sugestão de Garver e Mentzer (1999) e levou em consideração o exame dos resíduos padronizados. De acordo 
com Garver e Mentzer (1999), o pesquisador deve preocupar-se em obter um número pequeno de resíduos padronizados relativos aos indicadores de cada variável latente. Neste procedimento, foram consideradas unidimensionais as dimensões que apresentaram, para todos os pares formados por suas variáveis manifestas, resíduos padronizados menores do que 2,58 $(\mathrm{p}<0,05)$. As dimensões Inovatividade, Insegurança com a Informação e Insegurança pela falta de Contato Pessoal apresentaram resíduos abaixo de 2,58, verificando-se, assim, a unidimensionalidade destas dimensões. Já as dimensões Otimismo e Desconforto com o Constrangimento apresentaram alguns resíduos padronizados elevados, o que indica relativa fragilidade da propriedade de unidimensionalidade dessas dimensões.

A fim de buscar uma medida mais adequada de confiabilidade no âmbito da modelagem de equações estruturais, seguiu-se a sugestão de Bagozzi (1994) e Hair et al. (1998) para cálculo da confiabilidade composta. Para o modelo com 5 fatores obtiveram-se os valores 0,77 a 0,89. A avaliação dos resultados indicou que as dimensões apresentaram confiabilidade superior aos valores sugeridos na literatura: a partir de 0,50, com valores satisfatórios entre 0,70 e 0,90. Contudo a variância extraída não atingiu valores elevados, permanecendo entre 0,36 e 0,67 . Verifica-se, na literatura, contudo, que valores abaixo do padrão de 0,50 são comuns, mesmo em modelos que apresentaram bons índices de ajustamento. Klei, Etteson e Morris (1998) encontraram, em seu estudo, variâncias extraídas entre 0,32 e 0,54, mesmo apresentando um modelo com ajustamento bastante satisfatório. Da mesma forma, Viana (1999) obteve o mesmo intervalo de valores da variância extraída de um modelo sobre marketing de relacionamento, entre 0,36 e o,67.

Para a avaliação da validade discriminante, Fornell e Larcker (1981) sugerem um procedimento que consiste na comparação entre a variância extraída da dimensão e as suas variâncias compartilhadas (o quadrado do coeficiente de correlação) com as demais dimensões. A validade discriminante é positiva, quando todas as dimensões apresentam variâncias extraídas maiores do que as respectivas variâncias compartilhadas. Os resultados corroboram a validade discriminante, à medida que as dimensões Inovatividade, Desconforto com o Constrangimento, Insegurança com a Informação e Insegurança pela falta de Contato Pessoal, parecem distinguir-se; individualmente, apresentam variâncias extraídas maiores do que as suas variâncias compartilhadas com as outras dimensões, consideradas na análise; contudo a dimensão Otimismo apresentou variância extraída menor que a variância compartilhada com a Inovatividade, o que indica fragilidade no que se refere à propriedade de validade discriminante da dimensão otimismo. 
A validade convergente de cada dimensão individual foi verificada por meio do exame da significância estatística dos parâmetros estimados para cada uma das suas variáveis manifestas, a partir dos seus respectivos $t$-values (BAGOZZI; YI; PHILLIPS, 1991; GARVER; MENTZER, 1999). Os dados relativos às cargas padronizadas de cada dimensão confirmaram a validade convergente de todas as dimensões, considerando que nenhuma das variáveis manifestas analisadas registrou parâmetro estimado com t-value menor que 1,96.

A análise da validade convergente foi complementada pelo exame das medidas de ajustamento, estimadas para cada dimensão individual pela análise fatorial confirmatória. A consideração, neste caso, foi a de que ajustamentos satisfatórios reforçam a validade convergente dos constructos analisados (BAGOZZI; YI; PHILLIPS, 1991). A Tabela 1 apresenta as medidas de ajustamento para o modelo de 4 fatores e para o modelo de 5 fatores, com vistas à análise comparativa do desempenho de cada modelo (e seus fatores, individualmente).

\section{Tabela 1: Medidas de Ajustamento para os Dois Modelos}

\begin{tabular}{c|c|c|c|c|c|c|c|c|c}
\hline DIMENSão & $\chi^{2}$ & GL & $\chi^{2} / \mathbf{G L}$ & $\mathbf{P}$ & GFI & AGFI & TLI & CFI & RMSEA \\
\hline Otimismo & 169,28 & 31 & 5,4 & 0,000 & 0,95 & 0,92 & 0,91 & 0,94 & 0,07 \\
\hline Inovatividade & 81,85 & 14 & 5,8 & 0,000 & 0,96 & 0,93 & 0,94 & 0,96 & 0,08 \\
\hline $\begin{array}{c}\text { Insegurança pela falta } \\
\text { de Contato Pessoal }\end{array}$ & 15,25 & 3 & 5,0 & 0,002 & 0,99 & 0,95 & 0,95 & 0,98 & 0,07 \\
\hline $\begin{array}{c}\text { Insegurança com a } \\
\text { Informação }\end{array}$ & 3,16 & 2 & 1,5 & 0,206 & 0,99 & 0,98 & 0,99 & 0,99 & 0,02 \\
\hline Desconforto & 445,57 & 35 & 12,7 & 0,000 & 0,89 & 0,82 & $\mathbf{0 , 7 1}$ & $\mathbf{0 , 7 7}$ & $\mathbf{0 , 1 2}$ \\
\hline Insegurança & 685,09 & 27 & 25,3 & 0,000 & $\mathbf{0 , 7 9}$ & $\mathbf{0 , 6 6}$ & $\mathbf{0 , 6 9}$ & $\mathbf{0 , 7 7}$ & $\mathbf{0 , 1 8}$ \\
\hline
\end{tabular}

$\chi^{2} /$ GL (Qui-quadrado sobre graus de liberdade); GFI (Goodness-of-fit); AGFI (Adjusted Goodnessof-fit); TLI (Tucker-Lewis Index); CFI (Comparative Fit Index); RMSEA (Root Mean Square Error of Aproximation).

Observa-se, na Tabela 1, que o modelo de 4 fatores apresenta medidas de ajustamento abaixo do mínimo recomendado na literatura (HAIR et al., 1998) naquelas dimensões que sofreram modificações, dando origem ao modelo alternativo de 5 fatores. Os resultados evidenciam um fraco ajustamento da dimensão Desconforto, com 10 variáveis, pois os indicadores representados pela relação entre Qui-quadrado e graus de liberdade $(<5,0)$, TLI $(>0,90)$, CFI $(>$ $0,80)$ e RMSEA $(<0,08)$ apresentaram valores não aceitáveis. De forma similar, a dimensão Insegurança, com 9 variáveis, apresentou fraco ajustamento, com medidas de ajustamento fora dos padrões aceitáveis.

Além da análise individual dos fatores, buscou-se a validação das dimensões analisadas simultaneamente, de forma a obter o modelo de mensuração completo. A Tabela 2, a seguir, apresenta o resultado comparativo das medidas de ajustamento entre o modelo proposto por Parasuraman (2000) com 4 fatores, e o 
modelo resultante do presente estudo, com 5 fatores, utilizando-se a mesma base de dados.

\section{Tabela 2: Medidas de Ajustamento para os Dois Modelos Completos}

\begin{tabular}{lcc}
\hline & Modelo 4 Fatores & Modelo 5 Fatores \\
\hline Chi-square (p-level) & $2899.802(0.00)$ & $1770.592(0.00)$ \\
Degrees of Freedom & 579 & 445 \\
Chi-square / Degrees of Freedom & 5.0 & 3.9 \\
Goodness-of-fit Index (GFI) & 0.79 & 0.85 \\
Adjusted Goodness-of-fit (AGFI) & 0.75 & 0.82 \\
Tucker-Lewis Index (TLI) & 0.77 & 0.86 \\
Comparative Fit Index (CFI) & 0.79 & 0.87 \\
Root Mean Square Error of Approximation (RMSEA) & 0.07 & 0.06 \\
\hline
\end{tabular}

Observa-se melhor desempenho do modelo de 5 fatores, com relação às medidas de ajustamento para o modelo de mensuração completo. Tal constatação vem corroborar a adequação e validade do modelo com os 5 fatores avaliados, neste estudo, para mensuração da prontidão para tecnologia dos consumidores. Devese refletir, contudo, sobre a possibilidade de melhoria das medidas de ajustamento, se fosse possível incluir, nesta análise, a dimensão Desconforto com o Risco funcional e físico.

\section{Comparação dos Escores do TRI}

Uma forma alternativa para avaliação da validade de constructo do TRI envolveu a comparação dos escores dos respondentes do TRI, agrupados por categorias de posse e uso e categorias de prontidão para a tecnologia. Considera-se forte indício de validade de constructo a capacidade do TRI de discriminar usuários de não usuários de produtos e serviços baseados em tecnologia, ou de predizer comportamentos relacionados à compra desses produtos. Nesse sentido, as análises que seguirão pretendem fornecer resposta a esses questionamentos, por meio do exame das diferenças entre segmentos de consumidores e suas médias de prontidão para tecnologia.

Para determinar se há diferenças estatisticamente significativas entre os grupos comparados, foi realizada a análise de variância, por meio do One-Way ANOVA (com teste Tukey HSD de comparação múltipla das médias, para indicação dos grupos que diferem entre si). O objetivo dessa análise foi verificar se os indivíduos que já possuem, ou pretendem adquirir o produto, diferem daqueles que não pretendem adquirir, com relação ao seu nível de prontidão para tecnologia, verificado por meio da média de prontidão para tecnologia dos respondentes. Se a diferença se estabelece no sentido adequado, isto é, maior média de TR para os indivíduos que possuem o produto tecnológico, então, pode-se supor que o 
TRI possui poder preditivo e, portanto, constitui instrumento válido. Os resultados obtidos podem ser observados nas três tabelas a seguir.

A Tabela 3 apresenta os resultados referentes à relação entre o TRI e a posse de produtos e serviços baseados em tecnologia. A avaliação dos resultados permite identificar diferenças estatisticamente significativas entre as médias do TRI dos três grupos de respondentes, conforme categorias de posse.

\section{Tabela 3: Relação entre o TRI e a Posse de Produtos/Serviços Baseados em Tecnologia}

\begin{tabular}{lccc}
\hline & \multicolumn{3}{c}{ Categorias de posse } \\
\cline { 2 - 4 } Produtos/serviços & Já Possui & $\begin{array}{c}\text { Pretende adquirir } \\
\text { nos próximos } 12 \\
\text { meses }\end{array}$ & $\begin{array}{c}\text { Não pretende } \\
\text { adquirir }\end{array}$ \\
\hline TV por Assinatura & $2,83^{\mathrm{a}}$ & $2,73^{\mathrm{a}, \mathrm{b}}$ & $2,64^{\mathrm{b}}$ \\
\hline Secretária eletrônica & $2,81^{\mathrm{a}}$ & $2,71^{\mathrm{a}, \mathrm{b}}$ & $2,58^{\mathrm{b}}$ \\
\hline Telefone celular & $2,72^{\mathrm{a}}$ & $2,57^{\mathrm{a}, \mathrm{b}}$ & $2,27^{\mathrm{b}}$ \\
\hline Identificador de chamadas telefônicas/Bina & $2,77^{\mathrm{a}}$ & $2,80^{\mathrm{a}}$ & $2,63^{\mathrm{b}}$ \\
\hline Aparelho de Fax & $2,87^{\mathrm{a}}$ & $2,86^{\mathrm{a}}$ & $2,64^{\mathrm{b}}$ \\
\hline Palm Top & $2,97^{\mathrm{a}}$ & $3,05^{\mathrm{a}}$ & $2,69^{\mathrm{b}}$ \\
\hline Aparelho de DVD & $2,98^{\mathrm{a}}$ & $2,86^{\mathrm{a}}$ & $2,58^{\mathrm{b}}$ \\
\hline Computador em casa & $2,81^{\mathrm{a}}$ & $2,60^{\mathrm{b}}$ & $2,33^{\mathrm{c}}$ \\
\hline Internet em casa & $2,84^{\mathrm{a}}$ & $2,67^{\mathrm{b}}$ & $2,33^{\mathrm{c}}$ \\
\hline
\end{tabular}

*Médias com o mesmo sobrescrito não apresentam diferenças estatisticamente significativas. Médias com sobrescritos diferentes apresentam diferenças estatisticamente significativas no nível de 0,05 .

Como pode ser observado na Tabela 3, todos os produtos/serviços analisados refletiram diferenças entre as categorias de posse. Especificamente, consumidores que já possuem TV por assinatura, secretária eletrônica e telefone celular são significativamente mais propensos à tecnologia que aqueles que não pretendem adquirir estes produtos. Os consumidores que não pretendem adquirir aparelho de fax, identificador de chamadas telefônicas, Palm Top e DVD são menos propensos à tecnologia que aqueles que já os possuem ou pretendem adquiri-los nos próximos 12 meses. Para os produtos "computador em casa" e "internet em casa", observam-se diferenças significativas entre os três grupos em relação à sua prontidão para tecnologia, sendo a média do TRI mais elevada entre os que já possuem computador e internet e menos elevada entre os que não pretendem adquirir estes produtos.

Já a Tabela 4 contempla os resultados da análise de variância entre os segmentos de consumidores de serviços tecnológicos, conforme categorias de uso. 


\section{Tabela 4: Relação entre a TRI e o Uso de Serviços Baseados em Tecnologia}

\begin{tabular}{lccc}
\hline Serviços & \multicolumn{3}{c}{ Categorias de uso } \\
\cline { 2 - 4 } & $\begin{array}{c}\text { Usou nos últimos 12 } \\
\text { meses }\end{array}$ & $\begin{array}{c}\text { Pretende usar nos } \\
\text { próximos } 12 \text { meses }\end{array}$ & $\begin{array}{c}\text { Não pretende } \\
\text { usar }\end{array}$ \\
\hline Caixa eletrônico automático & $2,70^{\mathrm{a}}$ & $2,86^{\mathrm{a}}$ & $2,50^{\mathrm{a}}$ \\
\hline $\begin{array}{l}\text { Transação bancária por sistema telefônico } \\
\text { automatizado }\end{array}$ & $2,72^{\mathrm{a}, \mathrm{b}}$ & $2,86^{\mathrm{a}}$ & $2,57^{\mathrm{b}}$ \\
\hline Compra pela internet menor que R\$ 25,00 & $3,06^{\mathrm{a}}$ & $2,84^{\mathrm{b}}$ & $2,58^{\mathrm{c}}$ \\
\hline $\begin{array}{l}\text { Compra pela internet de R } \$ \\
25,00 \text { a R } \$ 250,00\end{array}$ & $3,18^{\mathrm{a}}$ & $2,90^{\mathrm{b}}$ & $2,58^{\mathrm{c}}$ \\
\hline $\begin{array}{l}\text { Compra pela internet maior } \\
\text { que R } \$ 250,00\end{array}$ & $3,10^{\mathrm{a}}$ & $2,97^{\mathrm{b}}$ & $2,64^{\mathrm{c}}$ \\
\hline
\end{tabular}

*Médias com o mesmo sobrescrito não apresentam diferenças estatisticamente significativas. Médias com sobrescritos diferentes apresentam diferenças estatisticamente significativas no nível de 0,05 .

Não foram constatadas diferenças significativas entre os grupos com relação ao uso de caixa eletrônico automático, ao contrário do estudo de Parasuraman (2000) que encontrou tais diferenças. Para a transação bancária por sistema telefônico automatizado, existem diferenças significativas entre os consumidores que pretendem usar nos próximos 12 meses (maior prontidão para tecnologia), e aqueles que não pretendem usar (menor prontidão para tecnologia). Finalmente, percebe-se que o comércio eletrônico parece evidenciar a maior diferença entre os consumidores: aqueles que realizaram compras pela internet nos últimos 12 meses, independentemente do valor envolvido, apresentam maior prontidão para tecnologia que o segmento que não realizou, mas pretende fazê-lo nos próximos 12 meses, que, por sua vez, diferencia-se do segmento que não pretende realizar compras pela internet, cuja média representa a menor prontidão para tecnologia.

Finalmente, assinalou-se, na Tabela 5, as médias encontradas em cada segmento de consumidores. O grupo com baixa prontidão para tecnologia apresentou média de 1,82; o grupo com média prontidão revelou média de 2,72; o grupo com alta prontidão obteve média de 3,55 . Os níveis de prontidão para tecnologia foram estabelecidos em baixo, médio e alto, sendo consideradas altas as médias iguais ou superiores à média geral do TRI $(2,69)$ mais um desvio-padrão; e baixas, as médias iguais ou inferiores à média geral menos um desvio-padrão. A Tabela 5 reporta os resultados atinentes ao grau de desejo dos consumidores (segmentados pelas médias de prontidão para tecnologia) de usufruir de situações ou serviços baseados em tecnologia considerados futuristas, ou em estágio de introdução. 


\section{Tabela 5: Relação entre a TRI e o Desejo de Uso Futuro de Serviços Baseados em Tecnologia}

\begin{tabular}{|c|c|c|c|}
\hline \multirow{2}{*}{ Serviços } & \multicolumn{3}{|c|}{ Categorias da Prontidão para Tecnologia } \\
\hline & $\begin{array}{l}\text { Baixa TR } \\
\text { (média }=1,82)\end{array}$ & $\begin{array}{l}\text { Média TR } \\
\text { (média }=2,72)\end{array}$ & $\begin{array}{c}\text { Alta TR } \\
\text { (média }=3,55)\end{array}$ \\
\hline Ter uma home-page da família na internet & $2,51^{\mathrm{a}}$ & $2,75^{\mathrm{a}}$ & $3,14^{\mathrm{b}}$ \\
\hline Usar um robô no caixa do supermercado & $2,87^{\mathrm{a}}$ & $2,73^{b}$ & $3,37^{b}$ \\
\hline Assistir a uma programa de televisão interativo & $3,57^{\mathrm{a}}$ & $4,34^{\mathrm{b}}$ & $4,51^{\mathrm{b}}$ \\
\hline $\begin{array}{l}\text { Comprar itens pequenos como ingressos para um } \\
\text { evento pela internet }\end{array}$ & $2,84^{\mathrm{a}}$ & $4,16^{\mathrm{b}}$ & $4,82^{\mathrm{c}}$ \\
\hline $\begin{array}{l}\text { Comprar itens grandes como um carro ou móvel } \\
\text { pela internet }\end{array}$ & $2,37^{\mathrm{a}}$ & $2,75^{\mathrm{a}}$ & $3,43^{\mathrm{b}}$ \\
\hline $\begin{array}{l}\text { Fazer ligações telefônicas por meio de um aparelho } \\
\text { que permita ver a outra pessoa e vice-versa }\end{array}$ & $4,56^{\mathrm{a}}$ & $5,28^{\mathrm{b}}$ & $5,21^{\mathrm{b}}$ \\
\hline Mandar uma mensagem de voz pela internet & $3,46^{\mathrm{a}}$ & $4,80^{\mathrm{b}}$ & $5,25^{\mathrm{c}}$ \\
\hline Navegar pela internet por meio de um aparelho de TV & $3,72^{\mathrm{a}}$ & $4,81^{\mathrm{b}}$ & $4,73^{\mathrm{b}}$ \\
\hline $\begin{array}{l}\text { Assistir a uma aula on-line/pela internet que } \\
\text { permitisse troca eletrônica de informações }\end{array}$ & $3,64^{\mathrm{a}}$ & $4,93^{\mathrm{b}}$ & $5,33^{\mathrm{c}}$ \\
\hline $\begin{array}{l}\text { Ler um livro de um cd ou internet com o auxílio de } \\
\text { um vídeo eletrônico portátil }\end{array}$ & $3,65^{\mathrm{a}}$ & $4,22^{\mathrm{b}}$ & $4,44^{\mathrm{b}}$ \\
\hline $\begin{array}{l}\text { Permitir que um computador ajude no diagnóstico e } \\
\text { tratamento de um problema médico }\end{array}$ & $4,71^{\mathrm{a}}$ & $5,10^{\mathrm{a}}$ & $5,03^{\mathrm{a}}$ \\
\hline $\begin{array}{l}\text { Ter um equipamento eletrônico de } \\
\text { emergência para sinalização da localização de } \\
\text { pessoas }\end{array}$ & $4,59^{\mathrm{a}}$ & $5,23^{\mathrm{b}}$ & $5,28^{\mathrm{b}}$ \\
\hline
\end{tabular}

*Médias com o mesmo sobrescrito não apresentam diferenças estatisticamente significativas. Médias com sobrescritos diferentes apresentam diferenças estatisticamente significativas no nível de 0,05 .

Os resultados revelam diferenças significativas entre os grupos para todos os serviços relacionados na Tabela 5, com exceção do penúltimo: Permitir que um computador ajude no diagnóstico e tratamento de um problema médico. Para todos os demais serviços, o grau de desejo do segmento com alta prontidão para tecnologia é significativamente maior que o desejo expressado pelo segmento com baixa prontidão. Especificamente, para 3 (três) serviços, há diferenças entre todos os segmentos. Esses serviços relacionam-se, de alguma forma, com a internet ou comércio eletrônico: Comprar itens pequenos como ingressos para um evento pela Internet; mandar uma mensagem de voz pela internet, assistir a uma aula on-line/pela internet que permitisse troca eletrônica de informações entre todas as partes. O grupo com baixa prontidão apresenta desejo significativamente menor de usufruir o serviço ou situação que o grupo com média prontidão. Este último, por sua vez, tem um desejo menor que o grupo com alta prontidão.

Os resultados apresentados nas Tabelas 3, 4 e 5 apontam diferenças estatisticamente significativas entre os segmentos de consumidores avaliados para a grande maioria dos produtos ou serviços tecnológicos. Mais que isso, as diferenças encontradas refletem a capacidade do Technology Readiness Index 
(TRI) de discriminar usuários de não usuários de produtos e serviços baseados em tecnologia, ou de predizer comportamentos. Resumidamente, consumidores mais predispostos possuem ou pretendem adquirir produtos ou serviços tecnológicos e expressam, de forma mais intensa, um desejo de usufruir serviços mais futuristas que aqueles menos predispostos.

\section{Implicações Gerenciais do Uso do TRI}

A partir do entendimento das dimensões constituintes da prontidão para tecnologia, um aspecto que deve ser considerado é a tipologia resultante do TRI. Tomando-se o modelo de 4 fatores proposto por Parasuraman e Colby (2001), é possível classificar os indivíduos em 5 tipos, assim denominados: exploradores, pioneiros, céticos, paranóicos e retardatários.

O segmento dos exploradores, por exemplo, apresenta altos índices de prontidão para tecnologia, com altos escores nas dimensões condutoras da adoção, otimismo e inovatividade; e baixos escores nas dimensões inibidoras, desconforto e insegurança. O segmento dos pioneiros divide com os exploradores altos níveis de otimismo e inovatividade, mas, ao mesmo tempo, apresenta níveis também altos de desconforto e insegurança. O grupo dos céticos revela escores baixos em todas as dimensões. O grupo dos paranóicos apresenta altos níveis de otimismo, mas revela níveis igualmente altos nas dimensões inibidoras da adoção. Este grupo apresenta, ainda, baixo grau de inovatividade. Finalmente, os retardatários representam o oposto dos exploradores, pois exibem baixos escores nas dimensões condutoras da adoção e altos escores nas dimensões inibidoras.

Cada segmento, determinado por um padrão de crenças e sentimentos a respeito da tecnologia, também pode apresentar diferenças demográficas e psicográficas, mas é suficientemente distinto para auxiliar as empresas na busca do melhor gerenciamento da relação cliente-tecnologia e conseqüente customização das estratégias de tecnologia. Desta forma, indivíduos considerados paranóicos necessitam de garantias técnicas de funcionamento e segurança, enquanto o grupo dos “céticos” precisam ser convencidos dos aspectos positivos do uso de tecnologia.

A utilização da prontidão para tecnologia constitui uma medida das atitudes e crenças dos indivíduos em relação à tecnologia extremamente útil na predição de comportamentos de adoção, na identificação de tipos distintos de indivíduos, e na previsão mais acurada de comportamentos futuros de clientes e produtos. 


\section{Considerações Finais}

O constructo prontidão para tecnologia e, particularmente, o Technology Readiness Index, constituem um avanço para o campo de estudo do comportamento do consumidor e para a disciplina de marketing como um todo. Este trabalho pretendeu contribuir para este avanço, no sentido de buscar a continuidade do esforço inicial despendido por Parasuraman (2000) e Parasuraman e Colby (2001). Buscou-se avaliar a aplicabilidade do Technology Readiness Index (TRI) no contexto brasileiro, a partir da análise de propriedades de unidimensionalidade, confiabilidade, validade convergente e discriminante, utilizando-se, para isso, o expediente da análise fatorial confirmatória (AFC). Adicionalmente, a validade de constructo foi verificada por meio da comparação dos escores dos respondentes do TRI, agrupados por categorias de posse, uso e prontidão para a tecnologia. A partir da avaliação realizada, tanto sob o ponto de vista teórico, quanto estatístico, considera-se que o Technology Readiness Index representa uma medida confiável e válida, medindo de fato aquilo que se propôs a medir, ou seja, a prontidão para tecnologia dos consumidores.

O teste ANOVA permitiu identificar diferenças entre os grupos analisados, refletetindo a capacidade do TRI de discriminar usuários de não usuários de produtos tecnológicos, ou de predizer comportamentos. Nesse sentido, consumidores mais predispostos possuem ou pretendem adquirir produtos ou serviços tecnológicos e expressam, de forma mais intensa, um desejo de usufruir serviços mais futuristas que aqueles menos predispostos. Essa direção preditiva aliada à capacidade discriminatória do TRI constitui um forte indicador de validade de constructo, à medida que os itens relacionados no instrumento realmente parecem medir a propensão dos indivíduos à adoção de produtos e serviços baseados em tecnologia.

Não foi confirmada, contudo, a estrutura de 4 fatores sugerida por Parasuraman e Colby (2001), tanto a partir de uma análise exploratória quanto confirmatória, verificada com o melhor ajustamento do modelo alternativo com 5 fatores. Nesse sentido, como sugestões para pesquisas futuras, ressalta-se, primeiramente, aquelas diretamente relacionadas aos resultados da avaliação da qualidade do TRI. Sugerese a reavaliação da dimensão identificada como Desconforto com o Risco funcional e físico, uma vez que não foi possível, como já dito anteriormente, acrescentá-la nas análises que envolveram o uso de modelagem de equações estruturais, como é o caso da técnica de análise fatorial confirmatória. Somente uma análise mais aprofundada pode indicar a necessidade de inclusão de outras variáveis relacionadas ao risco percebido, já que este é conceito que permeia sensivelmente as decisões de compra dos consumidores. 
Sugere-se, ainda, a reavaliação da unidimensionalidade e validade discriminante da dimensão otimismo que, neste estudo, não apresentou resultados satisfatórios. Certa ambigüidade em relação às dimensões de otimismo e inovatividade já havia sido relatada por Parasuraman (2000) na primeira etapa do desenvolvimento do TRI, quando alguns itens da escala apresentaram cargas fatoriais igualmente elevadas nos dois fatores. Esse resultado merece atenção e indica a pertinência de novas análises que confirmem, ou não, a necessidade de uma reespecificação das variáveis, a fim de que a dimensão otimismo apresente a validade discriminante, ora não verificada.

A partir do exposto, e com base nos resultados que, por ora, são apresentados, uma importante contribuição viria da continuidade dos estudos acerca da estrutura do TRI e suas dimensões. Desta forma, a futura proposição de uma tipologia baseada em facetas que incluem não somente a inovatividade do consumidor, mas elementos relacionados ao otimismo, desconforto com o constrangimento e com o risco funcional e físico, insegurança em relação à informação e à falta de contato pessoal, busca uma interpretação mais realista para os níveis de prontidão para tecnologia dos consumidores brasileiros.

\section{Artigo recebido em 01.11.2003. Aprovado em 17.05.2004.}

\section{NotA}

\footnotetext{
${ }^{1}$ A technology readiness é o conceito desenvolvido por A. Parasuraman e Charles Colby que deu origem ao National Technology Readiness Survey - NTRS, um extenso programa de pesquisas sobre as crenças da população norte-americana em relação à tecnologia. O conceito não é uma medida da competência técnica para lidar com tecnologia, nem isoladamente o retrato de um estado de espírito. Busca-se prever comportamentos (tendência à ação) a partir do entendimento do quão prontos os indivíduos estão para a efetiva adoção e uso de produtos/serviços tecnológicos; daí sua originalidade como conceito na literatura de marketing. Estar pronto para a tecnologia envolve apresentar características ou condições (combinação das dimensões condutoras e inibidoras) que permitem ao indivíduo agir. Nesse sentido, entendemos que o conceito de technology readiness é adequadamente refletido na expressão prontidão para tecnologia, aqui utilizada.
} 


\section{Referências Bibliográficas}

BAGOZZI, R. P.

Structural equations models in marketing research: basic principles. In: BAGOZZI, R. P. Principles of marketing research. Cambridge: Blackwell, 1994.

BAGOZZI, R. P.;

YI, Y.;

PHILLIPS, L. W.

Assessing construct validity in organizational research. Administrative Science Quarterly, v. 36, n. 3, p. 421458, sept. 1991.

\section{COWLES, D.}

Consumer perceptions of interactive media. Journal of Broadcasting and electronic media, v. 33, n. 1, p. 83-89, Winter 1989.

COWLES, D.;

CROSBY,L.

Consumer acceptance of interactive media in service marketing encounters. Service Industry Journal, v. 10, n. 3, p. 521-40, 1990.

DILLON, W. R. et al.

Good Science. Marketing Research, v. 9, n. 4, p. 22-31, Winter 1997.

FORNELL, C.;

LARCKER, D. F.

Evaluating structural equation models with unobservable variables and measurement error. Journal of Marketing Research, v. 18, n. 1, p. 3950, feb. 1981.
GARVER, M. S.;

MENTZER, J. T.

Logistics research methods: employing structural equation modeling to test for construct validity. Journal of Business Logistics, v. 20, n. 1, p. 33-57, 1999.

HAIR, J. F. Jr. et al.

Multivariate data analysis. 5. ed. Upper Saddle River: Prentice-Hall, 1998. p. 730.

MEUTER, M. L. et al.

Self-service technologies: understanding customer satisfaction with technology-based service encounters. Journal of Marketing, v. 64, n. 3, p. 50-64, july 2000.

MICK, D. G.;

FOURNIER, S.

Paradoxes of technology: consumer cognizance, emotions and coping strategies. Journal of Consumer Research, v. 25, n. 2, p. 123-47, sept. 1998.

MITCHELL, S.

Technophiles and technophobes. American Demographics, v. 16, n. 2, p. 36-43, feb. 1994.

PARASURAMAN, A.

Technology Readiness Index (TRI): a multiple-item scale to measure readiness to embrace new technologies. Journal of Service Research, v. 2, n. 4, p. 307-320, may 2000. 
PARASURAMAN, A.;

COLBY, C.

Techno-ready marketing: how and why your customers adopt technology. New York: The Free Press, 2001. p. 224.

ROSEN, L.D.;

SEARS D. C.;

WEIL M. M.

Computerphobia. Behavior Research Methods, Instruments, and Computers, v. 19, n. 2, p. 167-179, may 1987.

\section{TREZ, G}

Relação entre orientação para serviços ao cliente e performance das organizações. 2000. 130 f. Dissertação (Mestrado) - UFRGS: Programa de PósGraduação em Administração, Porto Alegre.
VIANA, D. A.

A proposição de um modelo sobre marketing de relacionamento no contexto business-to-business: avaliação inicial da indústria metalmecânica do Rio Grande do Sul. 1999. 126 f. Dissertação (Mestrado em Administração, ênfase Marketing) UFRGS: Programa de Pós-Graduação em Administração, Porto Alegre.

WEBER, K.;

ROEHL, W. S.

Profiling people searching for the purchasing travel products on the World Wide Web. Journal of Travel Research, v. 37, n. 3, p. 291-298, feb. 1999. 


\section{ANEXO}

\section{Quadro 1: Resultado da Tradução Reversa do Technology Readiness Index}

1. A tecnologia permite que as pessoas tenham mais controle sobre o seu dia-a-dia

2. Produtos e serviços que utilizam as mais novas tecnologias são muito mais convenientes de usar.

3. Você gosta da idéia de fazer negócios pelo computador, porque você não fica restrito ao hor ário comercial.

4. Você prefere usar a tecnologia mais avançada disponível.

5. Você gosta de programas de computador que lhe permitam adequar as coisas às suas próprias necessidades.

6. A tecnologia faz com que você fique mais eficiente no seu trabalho.

7. Você considera as novas tecnologias mentalmente estimulantes.

8. A tecnologia lhe dá mais liberdade de movimento.

9. Aprender sobre tecnologia pode ser tão recompensador quanto a própria tecnologia.

10. Você está seguro de que as máquinas seguirão as suas instruções.

11. Outras pessoas the pedem conselhos sobre novas tecnologias.

12. Parece que seus amigos estão aprendendo sobre as mais novas tecnologias mais do que você.*

13. Em geral, você está entre os primeiros do seu grupo de amigos em adquirir uma nova tecnologia logo que ela surge.

14. Normalmente, você consegue entender os novos produtos e serviços de alta tecnologia sem a ajuda de outros.

15. Você está atualizado com os últimos desenvolvimentos tecnológicos das suas áreas de interesse.

16. Você gosta do desafio de entender equipamentos de alta tecnologia.

17. Você tem menos problemas que outras pessoas para fazer a tecnologia trabalhar para você.

18. Os serviços de suporte técnico (por telefone ou internet) não ajudam, porque não explicam as coisas em termos compreensíveis.

19. Às vezes, você acha que os sistemas de tecnologia não são projetados para serem usados por pessoas comuns.

20. Não existe manual de produto ou serviço de alta tecnologia que seja escrito em uma linguagem simples.

21. Quando você utiliza o suporte técnico de um fornecedor de produtos ou serviços de alta tecnologia, às vezes você se sente como se alguém que sabe mais do que você estivesse tirando vantagem de você.

22. Na compra de um produto ou serviço de alta tecnologia, você prefere o modelo básico a um modelo com muitas características adicionais.

23. É constrangedor quando você tem problemas com algum equipamento de alta tecnologia, enquanto outras pessoas estão olhando.

24. Deveria haver cuidado ao substituir tarefas desempenhadas por pessoas pela tecnologia, pois novas tecnologias podem falhar.

25. Muitas das novas tecnologias apresentam riscos à saúde ou à segurança que não são descobertos até que as pessoas tenham utilizado a tecnologia.

26. Novas tecnologias tornam muito fácil para o governo e as empresas espionar as pessoas.

27. As tecnologias parecem sempre falhar no pior momento possível.

28. Você não considera seguro fornecer o número do seu cartão de crédito pelo computador.

29. Você não considera seguro fazer qualquer tipo de transação financeira pela internet.

30. Você tem receio de que as informações que você envia pela internet serão vistas por outras pessoas.

31. Você não se sente seguro em fazer negócios com uma empresa que só pode ser acessada pela internet.

32. Qualquer transação realizada eletronicamente deveria ser confirmada posteriormente por algo escrito.

33. Sempre que algo se torna automatizado, é necessário checar, cuidadosamente, se a máquina ou o computador não está cometendo erros.

34. O contato humano é muito importante quando se faz negócios com uma empresa.

35. Quando você liga para uma empresa, você prefere falar com uma pessoa do que com uma máquina.

36. Quando você fornece informação a uma máquina ou pela internet, você nunca pode ter certeza de que ela realmente chegou ao destino certo.

Nota: dimensão otimismo: variáveis 1 a 10; dimensão inovatividade: variáveis 11 a 17; dimensão desconforto: variáveis 18 a 27; dimensão insegurança: variáveis 28 a 36.

*Indica escore inverso. 